This PDF is a selection from a published volume from the National Bureau of Economic Research

Volume Title: Tax Policy and the Economy, Volume 23

Volume Author/Editor: Jeffrey R. Brown and James M. Poterba, editors

Volume Publisher: University of Chicago Press

Volume ISBN: 978-0-226-07654-6

Volume URL: http://www.nber.org/books/pote08-3

Conference Date: September 25, 2008

Publication Date: July 2009

Title: New Evidence on the Labor Supply Effects of the Social Security Earnings Test Author: Leora Friedberg, Anthony Webb

URL: http://www.nber.org/chapters/c10570

Chapter pages in book: $(1-35)$ 


\title{
New Evidence on the Labor Supply Effects of the Social Security Earnings Test
}

\author{
Leora Friedberg, University of Virginia and National Bureau of Economic Research \\ Anthony Webb, Boston College Center for Retirement Research
}

\section{Executive Summary}

This paper investigates the impact on labor supply of changes in the Social Security earnings test in 1996 and 2000. We highlight how inertia in labor supply choices influences responses to policy changes. We do this in two ways. First, we show that taking account of last year's employment status is important in estimating responses to current earnings test changes, a step that has not always been taken in the literature. Second, we test the effect of not only actual but also anticipated earnings test parameters that cohorts faced at earlier ages. This approach demonstrates that past and anticipated future rules influence current employment and earnings. Thus we identify an impact of earnings test changes on employment at ages that are younger than those directly affected and in years that follow the direct change. Finally, we show that earnings test changes that were initiated in 1996 had an effect, in addition to the changes in 2000 that have been recently studied by others. Overall, we predict that the elimination of the earnings test in 2000 raised employment among Health and Retirement Study respondents by around 2 percentage points at ages 66-69 and 3.5 points at age 65 , with gains persisting as exposed cohorts aged and also arising at younger ages due to the shock to anticipated earnings test rules.

\section{Introduction}

The earnings test, which reduces benefits for people who continue to work after claiming Social Security, has been altered more often and more substantially than most other Social Security provisions, always in the direction of encouraging more work at older ages. Yet, for those who understand fully the Social Security rules, it is a surprise that it has much if any impact on labor supply, as benefits lost to the earnings test are returned to beneficiaries later on in actuarially neutral form. A worker who loses current benefits to the earnings test gains a higher flow of benefits later on, and the expected present value of that flow equals the current loss for someone with an average lifespan. Thus, 
the average worker who wants to continue to work after becoming eligible for Social Security should make the decision on grounds other than the earnings test. ${ }^{1}$

In spite of this, popular guides to retirement planning make note of the earnings test but not of the actuarial adjustment arising from forgone benefits, suggesting that people may view it as a pure tax on work. Moreover, previous research shows that the earnings test has had substantial effects on hours choices among older people who continue to work. Friedberg $(1998,2000)$ found that Social Security beneficiaries bunched their earnings in significant amounts just at or below the threshold earnings where the earnings test begins to apply and that this bunching "moved" in response to earlier steps to liberalize the earnings test rules, for example, by shifting upward to the new higher thresholds that were implemented in 1978 and disappearing when the earnings test was abolished for ages 70-72 in 1983.

Our current research continues this analysis by studying major changes to earnings test rules that were legislated in 1996 and 2000. It also focuses on retirement as well as hours choices among workers, an important emphasis in light of recent trends in retirement. Following decades of decline, the average retirement age stabilized in the 1980s and has started to rise more recently (Friedberg 2007). The delays in retirement mean that growing numbers of workers are confronting the earnings test.

In theory, even if the earnings test is viewed as a tax, it will only affect retirement if labor supply is constrained in some way so that work hours must be high; otherwise, it is always possible to work less than the earnings test threshold and not face the earnings test penalty. The nature and importance of such constraints on labor supply choices remains uncertain.

By using new sources of longitudinal data on labor supply transitions and by testing for effects of not only current but also past earnings test parameters that cohorts faced, we show that constraints on labor supply and consequent persistence of labor supply choices affect responses to the earnings test. We find that employment as well as hours increased after the earnings test was liberalized. We also find that taking account of last year's labor force status is important in measuring responses to earnings test changes in the current year and that past and anticipated future earnings test rules, and not just the current rules, affect current labor supply.

We use our estimates to predict the effect of the elimination of the earnings test in 2000 on employment in the Health and Retirement 
Study (HRS), and we find resulting increases of around 2 percentage points at ages 66-69 and 3.5 points at age 65 . As the exposed cohorts then age, employment remains about a percentage point (1.5) higher in 2001 and about a half a percentage point (0.9) higher in 2002 for ages 66-69 (age 65). Moreover, employment rates at younger ages increase by about 1 percentage point due to the shock to anticipated earnings test rules.

The rest of this paper is organized as follows. In Section II, we discuss the earnings test rules along with theoretical predictions and past empirical analysis of the impact on labor supply. In Section III we describe the data and in Section IV the results from our analysis of the Current Population Survey and the Health and Retirement Study. We conclude in Section V.

\section{Background}

In this section, we discuss the earnings test rules along with theoretical predictions and past empirical analysis of the impact on labor supply. We distinguish between predictions when labor supply is freely chosen or is subject to constraints that can influence responses to the earnings test, and we discuss the degree to which previous studies recognize such constraints.

\section{A. The Social Security Earnings Test}

The impact of current earnings on benefits. Social Security beneficiaries who earn too much at particular ages suffer a reduction in their current Social Security benefits, with the benefits deferred to later ages, as we describe later. Beneficiaries between ages 62 and 64 in 2005 lost $\$ 1$ in benefits for every $\$ 2$ in earnings above an annual threshold of $\$ 12,000$. The rules at ages 62-64 have been stable since the 1970s, with the earnings threshold increasing with the rate of annual wage inflation.

In contrast, the rules faced at ages 65-69 have been looser since $1978 .{ }^{2}$ As highlighted in table 1, the earnings test threshold before 1996 was about one-third higher than it was for ages 62-64, and the benefit reduction rate was $33 \frac{1}{3} \%$ for earnings above the threshold. Legislation passed in 1996 then raised the threshold at ages 65-69 in stages. It jumped from $\$ 11,280$ in 1995 to $\$ 12,500$ in 1996; rose in scheduled annual increments of $\$ 1,000$ until reaching $\$ 15,500$ in 1999; and then was set to hit $\$ 17,000$ in $2000, \$ 25,000$ in 2001 , and $\$ 30,000$ in 2002. In 2000, however, a new law eliminated the earnings test above the Full Retirement 
Table 1

Earnings Test Rules

\begin{tabular}{|c|c|c|c|c|c|c|c|}
\hline \multirow[b]{2}{*}{ Year } & \multicolumn{3}{|c|}{ Younger Age Group } & \multicolumn{3}{|c|}{ Older Age Group } & \multirow{2}{*}{$\begin{array}{c}\text { Full } \\
\text { Retirement } \\
\text { Age }^{\mathrm{a}} \\
\text { (FRA) }\end{array}$} \\
\hline & Ages & $\begin{array}{c}\text { Earnings } \\
\text { Threshold } \\
(\$)\end{array}$ & $\begin{array}{c}\text { Tax } \\
\text { Rate } \\
(\%)\end{array}$ & Ages & $\begin{array}{c}\text { Earnings } \\
\text { Threshold } \\
(\$)\end{array}$ & $\begin{array}{c}\text { Tax } \\
\text { Rate } \\
(\%)\end{array}$ & \\
\hline 1989 & $62-64$ & 6,480 & 50 & $65-69$ & 8,880 & 50 & 65 \\
\hline 1990 & $62-64$ & 6,840 & 50 & $65-69$ & 9,360 & $33 \frac{1}{3}$ & 65 \\
\hline 1991 & $62-64$ & 7,080 & 50 & $65-69$ & 9,720 & $33 \frac{1}{3}$ & 65 \\
\hline 1992 & $62-64$ & 7,440 & 50 & $65-69$ & 10,200 & $33 \frac{1}{3}$ & 65 \\
\hline 1993 & $62-64$ & 7,680 & 50 & $65-69$ & 10,560 & $33 \frac{1}{3}$ & 65 \\
\hline 1994 & $62-64$ & 8,040 & 50 & $65-69$ & 11,160 & $33 \frac{1}{3}$ & 65 \\
\hline 1995 & $62-64$ & 8,160 & 50 & $65-69$ & 11,280 & $33 \frac{1}{3}$ & 65 \\
\hline 1996 & $62-64$ & 8,280 & 50 & $65-69$ & 12,500 & $33 \frac{1}{3}$ & 65 \\
\hline 1997 & $62-64$ & 8,640 & 50 & $65-69$ & 13,500 & $33 \frac{1}{3}$ & 65 \\
\hline 1998 & $62-64$ & 9,120 & 50 & $65-69$ & 14,500 & $33 \frac{1}{2}$ & 65 \\
\hline 1999 & $62-64$ & 9,600 & 50 & $65-69$ & 15,500 & $33 \frac{5}{3}$ & 65 \\
\hline 2000 & $\begin{array}{c}62 \text { until Dec } \\
\text { before reaches } \\
\text { FRA }\end{array}$ & 10,080 & 50 & $\begin{array}{l}\text { Jan until month } \\
\text { reaches FRA }\end{array}$ & 17,000 & $33 \frac{1}{3}$ & $\begin{array}{c}65+2 \\
\text { months }\end{array}$ \\
\hline 2001 & $\begin{array}{c}62 \text { until Dec } \\
\text { before reaches } \\
\text { FRA }\end{array}$ & 10,680 & 50 & $\begin{array}{l}\text { Jan until month } \\
\text { reaches FRA }\end{array}$ & 25,000 & $33 \frac{1}{3}$ & $65+4$ \\
\hline 2002 & $\begin{array}{c}62 \text { until Dec } \\
\text { before reaches } \\
\text { FRA }\end{array}$ & 11,280 & 50 & $\begin{array}{l}\text { Jan until month } \\
\text { reaches FRA }\end{array}$ & 30,000 & $33 \frac{1}{3}$ & $65+6$ \\
\hline 2003 & $\begin{array}{c}62 \text { until Dec } \\
\text { before reaches } \\
\text { FRA }\end{array}$ & 11,520 & 50 & $\begin{array}{l}\text { Jan until month } \\
\text { reaches FRA }\end{array}$ & 30,720 & $33 \frac{1}{3}$ & $65+8$ \\
\hline 2004 & $\begin{array}{c}62 \text { until Dec } \\
\text { before reaches } \\
\text { FRA }\end{array}$ & 11,640 & 50 & $\begin{array}{l}\text { Jan until month } \\
\text { reaches FRA }\end{array}$ & 31,080 & $33 \frac{1}{3}$ & $65+10$ \\
\hline 2005 & $\begin{array}{c}62 \text { until Dec } \\
\text { before reaches } \\
\text { FRA }\end{array}$ & 12,000 & 50 & $\begin{array}{l}\text { Jan until month } \\
\text { reaches FRA }\end{array}$ & 31,800 & $33 \frac{1}{3}$ & 66 \\
\hline 2006 & $\begin{array}{c}62 \text { until Dec } \\
\text { before reaches } \\
\text { FRA }\end{array}$ & 12,480 & 50 & $\begin{array}{l}\text { Jan until month } \\
\text { reaches FRA }\end{array}$ & 33,240 & $33 \frac{1}{3}$ & 66 \\
\hline
\end{tabular}

Source: U.S. Social Security Administration (2005).

${ }^{a}$ This is the FRA that applies for the cohort turning 62 in the given year.

Age (FRA). While the FRA used to be 65 , it was gradually raised by much earlier legislation to 66 and later to 67 beginning with those reaching age 62 in 2000. The high earnings thresholds set in 1996 (e.g., \$31,800 in 2005) now apply between the ages of 65 and the FRA.

Identification of earnings test effects in our analysis. In this paper, we emphasize that recent rule changes generated shocks that altered actual 
values of the earnings test threshold relative to what was anticipated by people at the affected ages and altered anticipated values for younger people. This variation, as shown in table 2, is richer than recent studies have emphasized. Panel A of table 2 shows the value of the earnings test threshold by year and age for cohorts born between 1928 and 1940. Panel B shows the values that would have been anticipated by the same cohorts when they reached age 62; we assume that they correctly forecasted the rate of wage inflation (and thus the normal growth in the annual value of the threshold) but not the legislation of 1996 and $2000 .^{3}$

This perspective reveals several interesting features. First, the 1996 jump in scheduled threshold values generated sizable shocks to earnings test rules, although other recent studies focused entirely on the 2000 elimination of the earnings test. Moreover, the 1996 and 2000 changes may be confounded. Earlier studies simply compared labor supply changes before and after 2000 to identify effects of the earnings test. Yet the elimination in 2000 should be considered against a baseline in which the earnings test threshold had risen for several years and would have hit $\$ 17,000$ in 2000, $\$ 25,000$ in 2001, and $\$ 30,000$ in 2002considerable amounts for people still working above the age of $65 .{ }^{4}$

In considering both changes together, we can see that the range of variation in anticipated earnings test rules stretches across numerous cohorts. The timing of shocks to earnings test parameters is indicated by shading in table 2 . In shaded cohort-year cells, actual threshold values rose above what would have been anticipated by the cohort at age 62 . The first cohort to experience such a shock was the 1927 birth cohort, which turned 69 in 1996 and saw a small jump in the threshold in their last year facing the earnings test. The last was the 1937 birth cohort, which turned 62 in 1999 and was surprised by the elimination of the earnings test above the FRA a year later.

The magnitude of the shocks is summarized in panel C of table 2, reporting the discounted present value of actual and anticipated threshold values, from an age-62 perspective, summed over ages $62-69 .{ }^{5}$ To understand the calculations, note that actual and anticipated present values are equal for the final cohorts, as they reached age 62 after 2000 and were not surprised by any rule changes.

The anticipated and actual present values of the thresholds diverge for birth cohorts 1927-37. The divergence is small for early cohorts, which experienced changes in threshold values as they neared age 70 . The gap jumps for the 1931 cohort. They turned 62 in 1993 and would have expected an earnings test threshold of about \$11,400 at age 65 in 1996 (it 


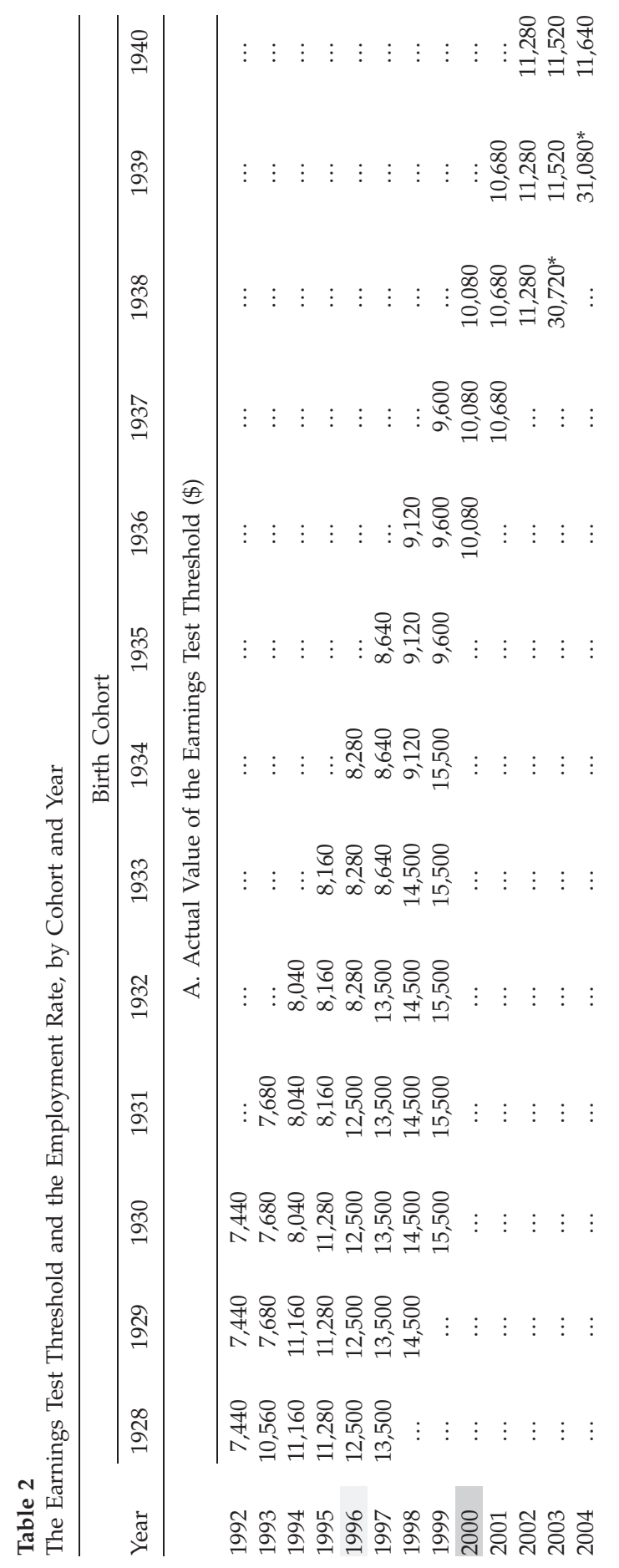




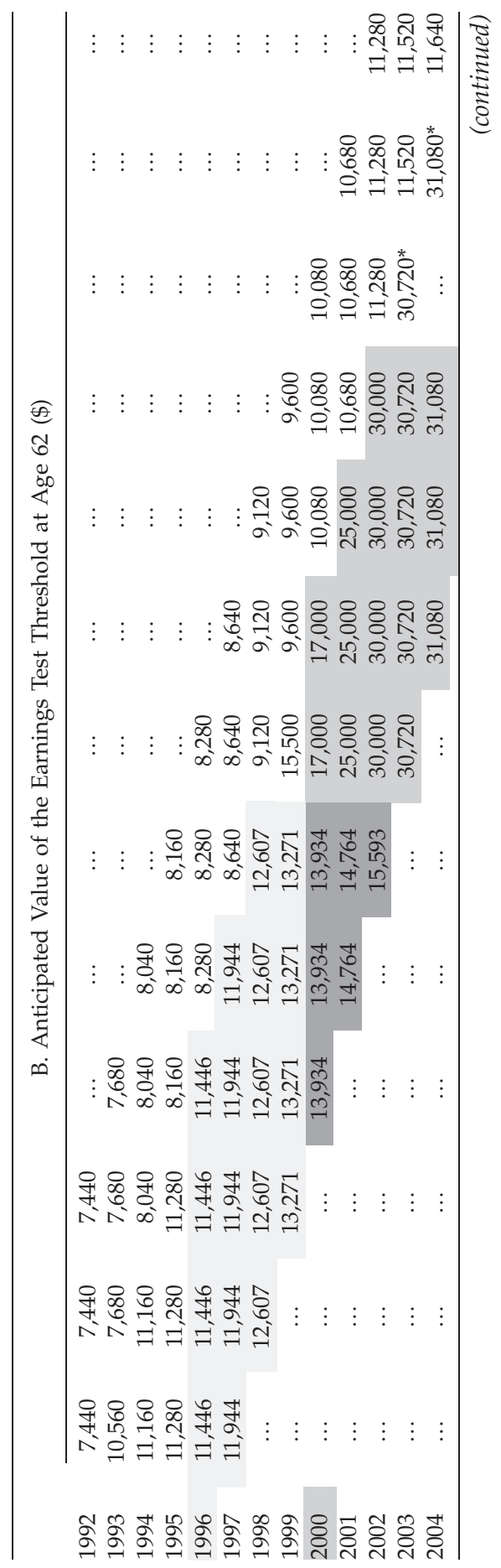




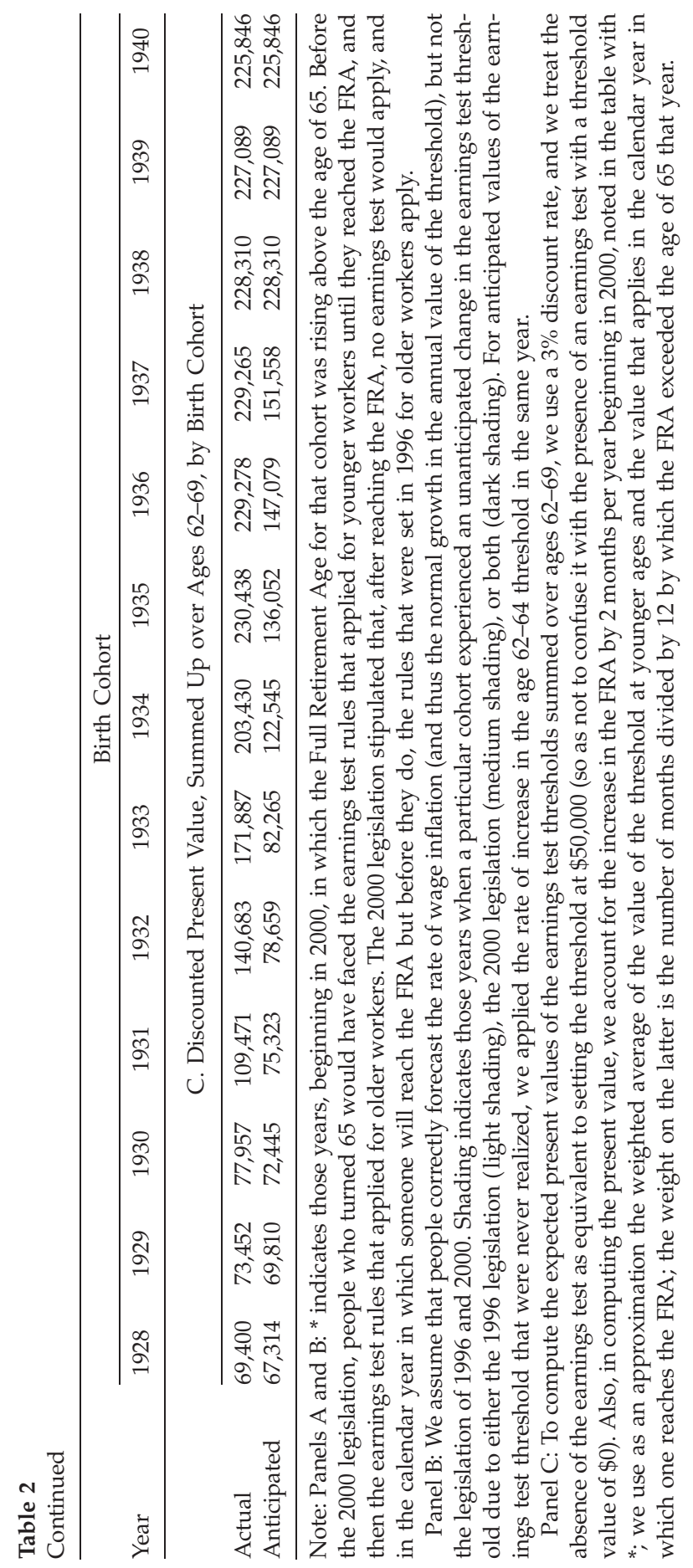


was actually $\$ 12,500$ ) and $\$ 13,900$ at age 69 in 2000 (when it was actually eliminated); this results in an anticipated present value of $\$ 75,323$, summed up at age 62 , and an actual present value of $\$ 109,471$, about one-third higher. The gap reaches a maximum for the 1935 cohort, which experienced an anticipated present value of $\$ 136,052$ and an actual present value of $\$ 230,438$. The gap narrows afterward but remains notable through to the final shock experienced by the 1937 cohort.

Our regressions will analyze how labor supply was affected by current and by anticipated future parameters. Anticipated rules can matter if labor supply choices have long-lasting consequences, for reasons that we review shortly. Moreover, if labor supply exhibits inertia, then current labor supply can also reflect the influence of earlier earnings test rules, so we include contemporaneous and anticipated parameters that were in place at younger ages as well. While our analysis is obviously reduced form, since we estimate the effect of policy parameters but not a fully specified model of labor supply, the use of past and future policy parameters can nevertheless identify the presence of important dynamic effects.

The deferral of benefits. Before we discuss the theoretical effects of the earnings test, we take note again of the rules governing the relationship between the earnings test and later benefits. Just as future benefits are raised for people who delay claiming Social Security in the first place, they are compensated with higher future benefits for each month's worth of benefits lost to the earnings test. Before the FRA, the actuarial adjustment raises future benefits by about $7 \%$ for each year's worth of lost benefits. Over the FRA, the Delayed Retirement Credit (DRC), which does the same, has risen gradually from 3\% in 1990 and will reach $8 \%$ in $2008 .{ }^{6}$ A $7 \%-8 \%$ credit is actuarially fair on average, so someone with average life expectancy and no borrowing constraints should be indifferent about the timing of benefit receipt.

These credits undermine the long-run fiscal gains from the earnings test and should reduce the impact of the earnings test on current labor supply. Many beneficiaries appear to react to the earnings test, nonetheless, probably because the credits are not well understood. The earnings test's impact is confirmed by the clustering of beneficiaries who keep their earnings right around the threshold value, as demonstrated in numerous papers mentioned later. Articles in Money and the Los Angeles Times describing the earnings test failed to note that future benefits are raised if current benefits are reduced. ${ }^{7}$ Similarly, Reimers and Honig $(1993,1996)$ found no evidence of increased labor force reentry when the DRC was raised. Consequently, we ignore their effects, as have many other researchers. 


\section{B. Theoretical Predictions}

In this subsection, we discuss predicted effects of the earnings test on labor supply under a variety of assumptions about the flexibility of labor supply choices.

Unconstrained labor supply. Figure 1 shows the piecewise linear budget constraint generated by the earnings test, while abstracting from other taxes for simplicity. Implicit in figure 1 are two important assumptions: the first, which we just discussed and maintain through our analysis, is that people view the earnings test as a tax rather than an actuarially fair deferral of benefits, and the second is that people can choose to work any number of hours at their going wage.

The resulting budget constraint has a kink at the earnings test threshold and a reverse kink when benefits are exhausted. The jump in the earnings test tax rate from 0 to $33 \%-50 \%$ at the kink is large in absolute terms and in comparison to most of the rest of the government tax and transfer system. Yet, the impact of the earnings test on labor supply is ambiguous, depending on where someone would locate on the budget constraint in its absence. Beneficiaries with earnings below the threshold experience no change in incentives and, hence, in labor supply due to the earnings test. For beneficiaries with somewhat higher earnings, the earnings test induces a substitution effect from facing the tax rate, leading to lower hours, and an income effect from the loss of benefits, leading to greater hours. The substitution effect will induce some beneficiaries to reduce earnings just to the kink at the earnings threshold.

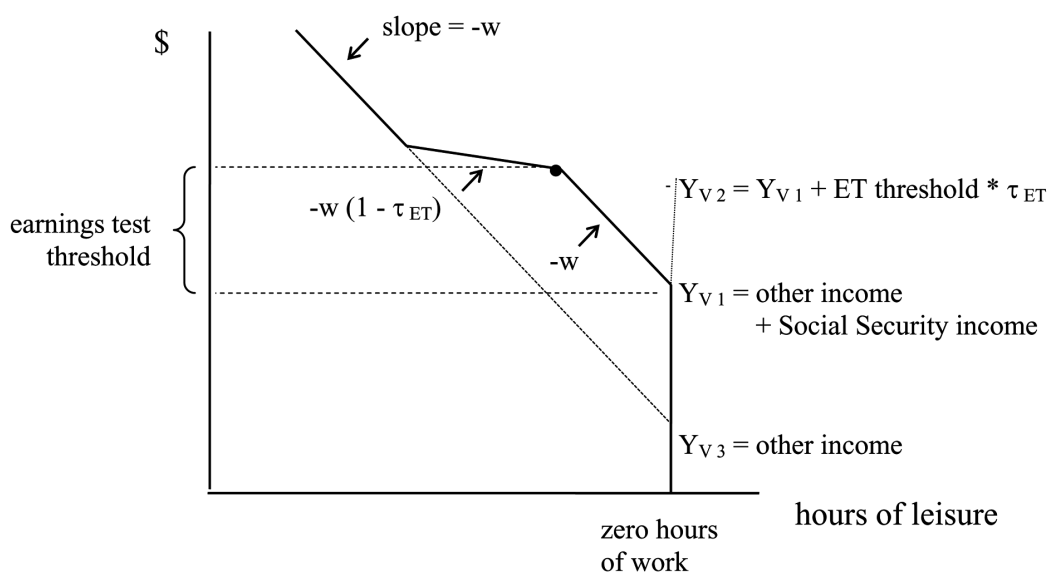

Fig. 1. The earnings test 
Last, beneficiaries with high enough earnings will face only an income effect from the loss of benefits and will work more.

Constraints on static labor supply. Considerable evidence suggests that workers face constraints on their labor supply choices. Such constraints include the concentration of work schedules at 40 hours per week, lower wages that are offered in part-time jobs compared to full-time jobs, and government regulation of overtime work and of the provision of fringe benefits to full-time workers. ${ }^{8}$ Thus, parts of the budget constraint with low hours of work may be either dominated by fixed costs that workers face or unavailable due to fixed costs that employers face. Other parts of the budget constraint may consist of points that offer bundles of wages and hours.

The effects of the earnings test will be altered if the budget constraint is limited by these factors. Imposing the earnings test will cause fewer people to adjust their labor supply, along with greater responses by those who do adjust. One unambiguous prediction distinguishes this model from the earlier one: the earnings test will now lead some people to retire, as long as nonparticipation dominates some discontinuous points on the budget constraint.

Constraints on labor supply transitions. In addition, some constraints may cause labor supply choices to be persistent over time. It is likely that there are fixed costs of changing jobs and even changing work hours within a job, as search, hiring, and training are costly to workers and employers. These costs may be exacerbated by the static constraints described above; for example, the difficulty of finding a job offering the particular wage-hours combination that a worker prefers may increase job search costs.

Such fixed costs will introduce inertia into labor supply decisions, with amplified effects for older workers who have shortened time horizons due to impending retirement. Even a worker who intends to postpone retirement indefinitely may find it difficult to credibly signal this intent to potential employers. Transition costs are probably even greater for people who seek to return to work after retiring and whose skills may be eroded or outdated.

For these reasons, we expect a much smaller immediate response to earnings test changes from people who are not working, given the difficulty of returning to the labor force. Even among those in jobs, we expect a muted impact early on. We expect to see a greater response as younger workers with time to adjust their plans age into the new rules.

The persistence of labor supply choices can also cause changes in labor supply at other ages not directly affected by a change in the earnings test. 
Knowing that the earnings test now disappears at the FRA instead of at 70 , people in their early 60 s might postpone retirement to take advantage of the higher return from working in their late 60s. They would do so if the gain from returning to the labor force after retirement in order to work after the FRA is dominated by the gain from staying in their jobs in the interim. Similarly, people who are now induced to continue working in their late 60s may stay in the labor force into their 70s, while before they would not return to the labor force upon reaching 70 .

These considerations expand the range over which the earnings test may affect labor supply but also create empirical difficulties. A common strategy in the recent literature is to use slightly younger and older workers as control groups to difference out other trends in labor supply affecting the treatment group over the same period. These hypothesized spillover effects of the earnings test undermine that strategy. ${ }^{9}$

\section{Empirical Literature}

The empirical approaches taken in studies of the earnings test can be divided into three basic types-simple analysis of bunching at the earnings test kink, regressions of labor supply on earnings test parameters, and estimation of structural labor supply models. The studies also differ in the data and time periods that they study. A careful analysis of these differences helps explain the mixed results from this literature.

Bunching at the earnings threshold. Many papers have demonstrated that workers cluster at the earnings test threshold (Burtless and Moffitt 1985; Vroman 1985; Friedberg 1998, 2000; Gruber and Orszag 2003; Haider and Loughran 2006; Song and Manchester 2007). Friedberg (2000) showed that bunching of earnings at the threshold is statistically significant and shifted significantly when earnings test rules changed. Clusters of beneficiaries appeared at the new higher threshold after it was raised in 1978 for ages 65-71 and disappeared after the earnings test was eliminated in 1983 for ages 70-71. Haider and Loughran showed that even more bunching is evident when using accurate administrative data on earnings instead of self-reported data. Most recently, Song and Manchester used quantile regressions and found significant increases in earnings at ages 65-69 after 2000 , concentrated over a region of the earnings distribution that lay somewhat above the earlier kink, and significant decreases over a region below the kink.

The magnitude of bunching at the kink in the budget constraint makes it clear that older workers enjoy some degree of flexibility in their labor supply choices, in line with Ruhm's (1990) observations 
about the prevalence of switches into "bridge jobs" after exits from career jobs. Also, older workers are much more likely to work part-time than prime-age workers are. ${ }^{10}$ Thus, the importance for older workers of limits on part-time work, difficulties in switching jobs, and other constraints remains an open question.

The appeal of studying bunching lies in its simplicity. It provides a straightforward test that the earnings test has an impact, since it does not require making inferences about where workers would otherwise locate on the budget constraint in the absence of the earnings test. ${ }^{11}$ The limitation of such analysis is that, without a model, it provides limited information about responses to other possible changes in the earnings test. While Saez (2005) shows how to infer the local compensated substitution elasticity from the magnitude of bunching at a convex kink, that approach does not identify the income elasticity, which Friedberg (2000) finds to be relatively important in magnitude for this age group, and its use has not been extended to budget constraints that are discontinuous due to the reasons outlined earlier.

Labor supply regressions. Another approach has been to estimate average labor supply responses to earnings test parameters, with the goal of analyzing aggregate responses while avoiding assumptions required to specify labor supply preferences. Recent studies have focused on the 2000 change, and some analyzed changes that occurred in 1990 and earlier, but none have examined the increase in the earnings threshold that began in 1996. These reduced-form studies estimated how work and earnings relate to earnings test parameters, such as the earnings test threshold and tax rate (Gruber and Orszag 2003) or dummies for the earnings test being in place (Tran 2005; Haider and Loughran 2006; Song and Manchester 2007). ${ }^{12}$

This estimation approach cannot separately identify conflicting income and substitution effects on hours of work, which again leaves us unable to extrapolate from the estimates to other possible changes in the earnings test. It can be used, though, to test one unambiguous prediction noted above- the earnings test may induce people to retire if labor supply is constrained in some way. Tran (2005), Haider and Loughran (2006), and Song and Manchester (2007) all show that employment at ages 65-69 increased after the 2000 elimination of the earnings test. Moreover, they show that this effect was stronger among those already in the labor force and increased in magnitude over time, so constraints that generate persistence in labor supply choices appear to be important. ${ }^{13}$ The first part of our empirical analysis builds on this approach by using different data sets and more post-2000 data, through 
2005, and, importantly, by looking at the 1996 as well as the 2000 change. ${ }^{14}$ The second part of our analysis investigates responses to not only current but also past and anticipated future earnings test rules.

Estimation of structural labor supply models. A structural model formally models the impact of the earnings test on after-tax wages and income and, hence, on labor supply. As an example, Friedberg (2000) estimated a truncated maximum-likelihood model of the choice of work hours among workers, using repeated cross-sections covering time periods before and after changes in the earnings test rules. Burtless and Moffitt (1985), Gustman and Steinmeier (1986), Berkovec and Stern (1991), and Rust and Phelan (1997) used longitudinal data to estimate structural retirement models, allowing for distinct wages for full-time versus part-time work. Burtless and Moffitt treated the earnings test as a pure tax, while Gustman and Steinmeier incorporated the deferral of benefits. Both estimated small effects of the earnings test on labor supply. This may be a consequence of estimating a full model of retirement, which inevitably focuses more attention on finding parameter values to explain the large numbers who retire than on the relatively smaller numbers who continue to work and face the earnings test. It may also arise from modeling the budget constraint in this fashion, since it requires simplifying the budget constraint to a full-time and a part-time wage-hours bundle and also imputing those bundles.

The most detailed recent treatment of the earnings test is seen in extensions of Gustman and Steinmeier's analysis, especially in their 2004 paper. They use HRS data through 2002 and thus analyze the 1996 and some of the 2000 effects, and they predict significant and large effects of the elimination of the earnings test. Yet their model limits how the earnings test can affect behavior in important ways. They allow for some constraints on labor supply choices by assuming a single full-time and part-time job option, though they do not directly incorporate costs of changing jobs or reentering the labor force. They assume that everyone is aware of all earnings test rules, including the increase in future benefits due to current benefits forgone. The main innovation in their model is to allow for differences in discount rates, so the reaction to the elimination of the earnings test is concentrated among people who, they infer, have a high discount rate.

Structural models like this one are attractive in providing coherent predictions about responses to earnings test changes and about labor supply parameters more broadly. However, such models face difficulties in capturing heterogeneity in the types of restrictions that people face in their labor supply choices and in their assumptions about awareness of 
government program rules. Therefore, there is some appeal in reducedform studies that can reveal the impact of such constraints without having to make a formal choice about how to model them.

\section{Data}

We use two data sources that report employment transitions and cover a period from before 1996 until after 2000. The longitudinal Health and Retirement Study (HRS) was not used in earlier studies of the earnings test except in the structural analysis of Gustman and Steinmeier (2004), while the March Current Population Survey (CPS) has not been used to analyze employment transitions in response to the earnings test as we do here.

Current Population Survey. We use the March CPS to focus on employment and single-year transitions in employment. The CPS is a nationally representative survey of employment status covering well over 100,000 individuals per month. The March supplement to the CPS reports information for the previous year's sources of income (allowing us to determine everyone's location on last year's budget constraint in relation to the earnings test) and labor supply (allowing us to analyze labor force transitions into and out of work and across employers). ${ }^{15}$

We select everyone in the CPS aged 55-74 between the years of 1992 and 2005. The resulting sample has, on average, 1,000-1,500 people per age per year. In all of our analysis, we use survey weights so that our statistics are nationally representative. ${ }^{16}$ We can identify age only in March, rather than on birthdays, so our knowledge of each respondent's earnings test parameters at transitional ages is imprecise. We define as those working last year anyone who worked at least 1 week. We define as those working now anyone who reports being at work or in a job but absent from work during the survey week.

Statistics on employment and earnings for the sample are shown in table 3. Employment rates rise through the period, as documented in Friedberg (2007), but the timing differs across age groups, with greater gains during the 1990s for ages 55-61, throughout the period for ages 62-64, and in the 2000s for ages 65-69.

Health and Retirement Study. The HRS is an extremely detailed, nationally representative panel survey of older Americans that is conducted every 2 years. It can be used to follow employment transitions from 1992 on. While it collects much more detailed information on labor supply and income, its primary disadvantages relative to the CPS is the smaller sample size and the absence of the full age ranges of people who might be affected by the earnings test. 
Table 3

Means (Standard Errors) of Key Variables

\begin{tabular}{lcccc}
\hline & \multicolumn{4}{c}{ March Current Population Survey, 1992-2005 } \\
\cline { 2 - 5 } & Age 55-61 & Age 62-64 & Age 65-69 & Age 70-74 \\
\hline Age & $57.8(2.0)$ & $63.0(.8)$ & $66.9(1.4)$ & $71.9(1.4)$ \\
Worked last year & .705 & .491 & .296 & .169 \\
If worked last year: & & & & \\
$\quad$ Real earnings last year & $46,749(53,686)$ & $39,568(52,337)$ & $30,582(48,022)$ & $25,705(46,689)$ \\
$\quad$ Working now & .900 & .798 & .760 & .744 \\
$\quad$ Full-time last week & .791 & .662 & .501 & .398 \\
Working last week & .642 & .399 & .232 & .131 \\
If worked last week, & & & & \\
$\quad$ worked full-time & .787 & .656 & .494 & .392 \\
Working last week: & & & & \\
$\quad$ 1992-95 & .616 & .364 & .209 & .116 \\
1996-99 & .641 & .393 & .219 & .126 \\
$\quad$ 2000-2005 & .654 & .422 & .256 & .144 \\
$N$ & 126,352 & 45,817 & 71,023 & 62,770 \\
\hline
\end{tabular}

Note: The CPS samples are weighted using March supplement weights to make the statistics nationally representative.

The main cohort of interest is the Original HRS cohort. It consists of 12,521 individuals born in 1931-41 and so aged 51-61 in 1992 and 59-69 in 2000, along with their spouses. In order to analyze people aged 58-74 in every year from 1992 on, we add respondents from other cohorts. The AHEAD (Assets and Health Dynamics of the Oldest Old) cohort consists of individuals born before 1923 and thus aged 70+ in 1992. The CODA (Children of the Depression) cohort was born in 1923-30, entered in 1998, and hence were aged 62-69 in 1992, at the beginning of the period we examine. The WB (War Babies) cohort was born in 1942-47, also entered in 1998, and were 57-62 in 2004, at the end of the period we examine.

Respondents in the HRS were asked to consent to having their records linked to data on earnings reported to the Social Security Administration. ${ }^{17}$ We used these linked earnings data through 2004 to determine annual employment status, although this will miss workers in noncovered jobs, primarily those working for some state and local governments.

\section{Empirical Results}

We begin by showing graphs of work, full-time work, and earnings by age group and year preceding and following the 1996 and 2000 earnings test changes. Because it can be difficult to visually distinguish aggregate labor supply trends from responses to the earnings test, we then employ a 
regression framework to identify shifts in labor supply that coincide with and follow changes in earnings test parameters, and we specifically quantify how changes in anticipated earnings test rules affect labor supply. The analysis begins in 1992, which provides a few years to identify labor supply patterns before the 1996 change. The analysis ends in 2003-5, depending on the data set and the outcome variable that we focus on.

\section{A. Graphical Analysis}

Work and nonwork. Analysis of 1-year labor supply transitions for large samples in the CPS demonstrates the persistence of labor supply choices. Figure 2 shows employment rates for age groups from the late 50s to early 70s between 1993 and 2005. The stock of people working in jobs appears in figure $2 A$, while the flows into work by people who were working or not in the previous year appear in figure $2 B$ and $2 C$.

These flows reveal two general features. First, the majority of people working in a given year continue to work in the next year (see fig. $2 B$ ). The survival rate in work diminishes by age but remains at over $65 \%$ even for ages $70-74$. Second, figure $2 C$ shows that very few people return to work after not working at all in the previous year. The hazard rate into work is always under $5 \%$ and diminishes with age. ${ }^{18}$

Next we show that employment flows reveal more about the earnings test than does the stock of employment. In figure $2 A$ we see that the employment rate at ages 66-69 shows small blips upward in 1996 and 2000; however, employment increased gradually over this period for workers at all ages from 55 and up. ${ }^{19}$ The flows in figure $2 B$ and $2 C$ reveal clearer responses.

At ages 66-69, the flows continuing to work and returning to work both rise in 2000, while the flow continuing to work rises in 1996 as well. In figure $2 C$, the jump in the flow returning to work, while statistically significant, subsided after a single year. This back-to-work rate almost doubled from slightly under $1 \%$ in the late 1990 s to $1.7 \%$ in 2000 , but it accounted for less than one-fifth of the overall gain in the employment rate in 2000, compared to the late 1990s average. Moreover, the immediate drop back to earlier rates suggests that slightly younger workers promptly adjusted their exit decisions.

Meanwhile, the percentage staying in a job at ages 66-69 shown in figure $2 B$ rose from $73 \%-75 \%$ in the early 1990 s to $77.3 \%$ in 1997 , then dropped a little, and then rose to $78.1 \%$ in 2000 and peaked at $81.2 \%$ in 2004. Also interesting are the gains in the percentage of slightly older and younger workers, aged 62-64 and 70-74, staying in jobs after 1996 

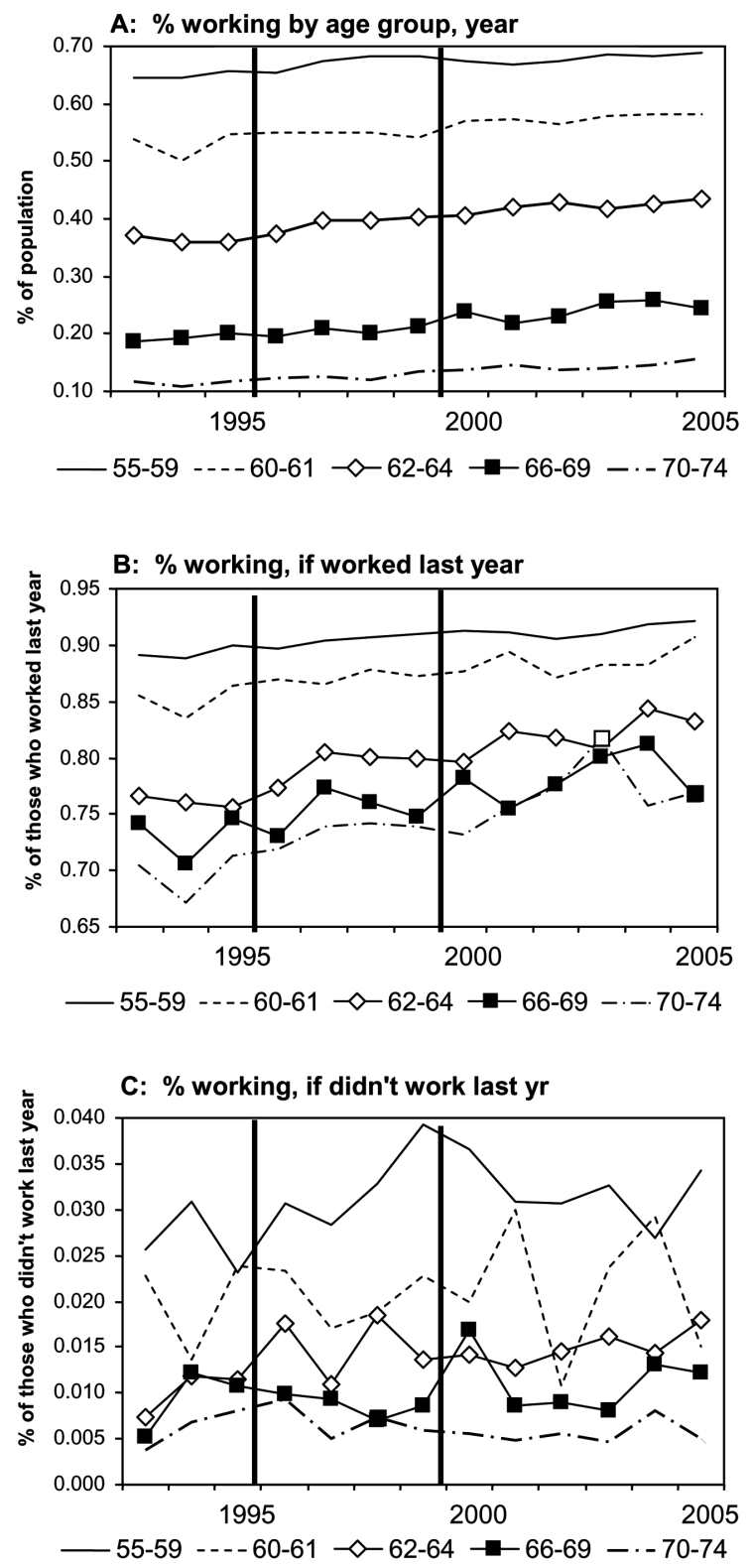

Fig. 2. Source: Data from March Current Population Surveys of 1992-2005. Additional details are provided in the text. 
and 2000. The increase for older workers appears with a lag. These effects suggest that younger and older groups who were not directly subject to the rule changes also respond to the earnings test.

Next we will decompose these gains for full- and part-time workers and along different parts of the earnings distribution. After that, we will use regression analysis to help sort out underlying shifts in labor supply from those that coincide with and follow the earnings test legislation.

Full- and part-time work. Figure $3 A$ and $3 B$ shows the percentage of people working full-time and part-time last week, among people who worked last year. Conditioning the sample on working last year focuses on those who are most responsive to rule changes. Furthermore, we expect different responses by work hours since working full-time often subjects beneficiaries to the earnings test.

The graphs suggest that people responded to earnings test liberalization by staying longer in full-time work, as predicted. The percent
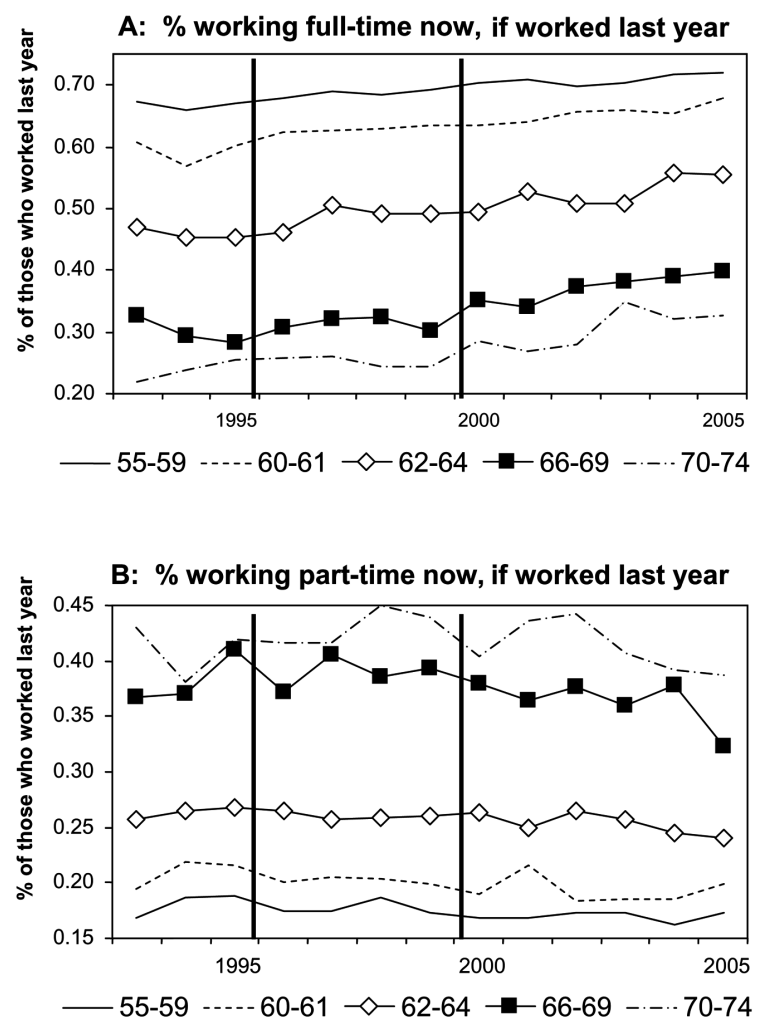

Fig. 3. Source: Data from March Current Population Surveys of 1992-2005. Additional details are provided in the text. 
working full time at ages 66-69, among those working last year shown in figure $3 A$, rose a little after 1996 and by more after 2000, and in a gradual fashion. Looking at part-time work in figure $3 B$, we see that there was no apparent change after 1996, so the gain in full-time work was fed by a drop in retirement. In contrast, part-time work rates declined after 2000, contributing to the increase in full-time work. As we saw with employment, full-time work rates also rose for slightly older and younger workers not directly affected by the rule changes.

Annual earnings. As we discussed earlier, liberalizing the earnings test should have differing effects, depending on how much someone was initially earning. We look for evidence of these differences by building on the approach of Manchester and Song (2007), who examined how quantiles of the earnings distribution of workers shifted before and after 2000. They found that earnings between roughly the 30th and 40th percentiles declined somewhat, and earnings between the 60th and 80th percentiles-which are in the vicinity of the earnings test threshold values before 2000-rose considerably.

In order to analyze how responses differ based on last year's earnings, we analyze data from the CPS. We compute percentile values of real earnings (measured in 2005 dollars) ${ }^{20}$ for workers by age group and year, and we track these percentile values over time. We focus on earnings between the 30 th and 40 th percentiles and between the 60 th and 80 th percentiles. ${ }^{21}$

Figure $4 A$ reports average real earnings between the 60th and 80th percentiles by age group and year, and figure $4 B$ reports the same for the 30th and 40th percentiles. In figure $4 A$, real earnings at the 60th80th percentiles for people aged 66-69 rose following the 1996 and 2000 changes. Interestingly, the gain is somewhat greater after 1996, which Manchester and Song do not study. Also, real earnings at precisely that part of the earnings distribution did not rise for slightly younger and older groups, although their overall employment rose. In figure $4 B$ there is little change in real earnings in the 30th-40th percentile range associated with either the 1996 or 2000 rule changes. This may occur because our data set is relatively small and our measure of earnings less accurate, compared to the data that Manchester and Song use.

\section{B. Regressions}

Approach. At this point, we use regression analysis to clarify the basic patterns laid out above. This helps sort out background changes in employment from responses to the earnings test, and it relates those responses to 
A: Real average earnings of workers, in $60-80^{\text {th }}$ percentile of distribution

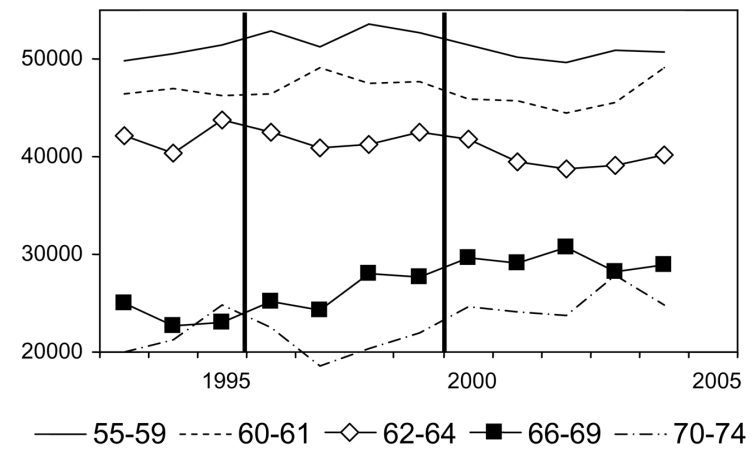

B: Real average earnings of workers, in $30-40^{\text {th }}$ percentile of distribution

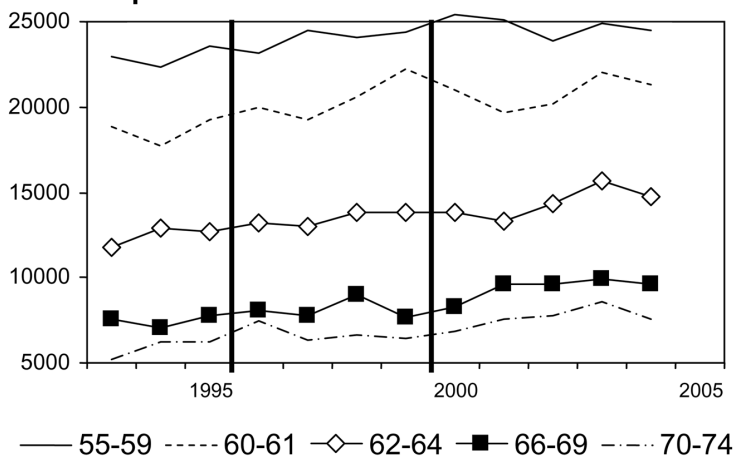

Fig. 4. Source: Data from March Current Population Surveys of 1992-2005. Additional details are provided in the text.

the magnitude of the earnings test changes. We exploit variation in earnings test parameters experienced by cohorts at different ages and in different years. This approach identifies the presence of dynamic effects resulting from changes in earnings test parameters by comparing estimated effects on labor supply of only current earnings test parameters, compared with past and anticipated future parameters. However, we cannot discern the full extent of these effects, given inherent limitations of our stripped-down approach that are discussed below.

To undertake this analysis, we compute means by age and year of the variables we analyzed above-employment, full-time employment, and earnings at different parts of the earnings distribution - and regress the cell means on earnings test parameters. The parameters include not 
just dummies for the earnings test being in place, as in much of the recent research, but also the value of the earnings test threshold. This offers a way to incorporate a great deal of additional variation from the 1996 and 2000 rule changes. While Gruber and Orszag (2003) included the current values of both variables (the earnings threshold and earnings test dummy) as well, we extend the analysis by adding values that are anticipated in the future and that were experienced in the past. Last, we include a full set of age and year dummies to difference out fixed age and time patterns in labor supply.

In total, we will use four variables that reflect currently applicable and future earnings test thresholds for cohorts at their current age and when the cohort is age 62 (or age 65 in another set of estimates), along with four parallel variables for earnings test dummies. Thus, the first of the four variables are the current earnings threshold and the current earnings test dummy. The second are the present value of the threshold and earnings test dummy that are anticipated from the current age until 69. As we explained in reference to table 2, we assume that people anticipate normal increases in the threshold associated with wage inflation, but not law changes. We depart from table 2 by setting the value of the earnings threshold at zero when there is no earnings test; while we chose a high value (of $\$ 50,000$ ) for exposition purposes when using table 2 to describe the identifying variation, in the regressions the earnings test dummies control for these instances. Last, we include a third and fourth set of variables that are analogous to the current and anticipated values just described, except that they are the values experienced by the cohort at age 62 (or at age 65).

A few limitations of this stripped-down approach need to be recognized. We hypothesize that the estimated coefficients are negative for the earnings test dummy (as the earnings test leads people to limit work) and positive for the earnings test threshold (conditional on the earnings test being in place). Yet, if the latter is too positive relative to the former, then eliminating the earnings test (and setting both the threshold and dummy to zero) would reduce labor supply. This problem does not arise in most of our results, while a structural model would avoid this naturally. Moreover, this reduced-form approach cannot capture all of the dynamic effects that might arise. In our formulation, we will miss some responses that generate persistence at ages other than 62 and 65 . This limitation arises because we cannot control for changes in four values - the annual and anticipated thresholds and earnings test dummies-at every single past age. Capturing these effects would require a structural model that formalizes the impact of 
both expectations and dynamic constraints of the type that we have highlighted. Thus, our analysis identifies the presence of dynamic effects at some ages, rather than their full consequences.

In order to define our sample for the regression analysis, we use ages 62-74 so as to focus on those affected by past and present earnings test rules. Our time period covers the years 1992 to 2003-5 (depending on the data set and variable) so as to include a few years before the 1996 and after the 2000 changes. We also limit the sample by beginning with the 1925 birth cohort, which turned 65 in 1990, since earlier cohorts experienced a higher benefit reduction rate when they turned 65 before 1990, and that might have altered their labor supply after age 65.

Regression results. By way of comparison, we first report results in table 4 that include only the current value of the earnings test threshold and earnings test dummy, along with a full set of age and year effects. A higher value of the current threshold raises labor supply in table 4, as measured by employment, full-time employment, and earnings, and removing the earnings test raises labor supply as well.

Importantly, the results differ somewhat depending on the measure of labor supply. The estimated effects of earnings test parameters are generally significant except when using measures of current labor supply from the CPS. These measures report whether someone had a job or worked full-time last week, while the other measures report whether someone worked at all or usually worked full-time or what they earned over a full year, both for this year (in the HRS) and last year (in the CPS). Since the earnings test depends on labor supply and earnings for the year, the variables based on last week's status measure annual labor supply with more error, which may explain the weaker results.

The full set of results for the age- 62 and age- 65 perspectives is reported in tables 5 and 6, respectively. Now, current values of earnings test parameters are less important when we include measures of future and past parameters. The current values remain significant in a few instances, and more often in the age-65 analysis, while the variables reflecting future and past values are significant in some of the other specifications. Joint $F$-tests give only occasional evidence of multicollinearity, but in any case we will consider the joint effect of all the coefficients in simulations that we undertake shortly. ${ }^{22}$

The upper and middle panels of table 5 show results for employment and full-time employment, and the lower panel shows results for earnings on different parts of the earnings distribution. In the upper panel, we find significant effects of values anticipated at age 62 on employment, as measured by having a job last week. A higher present value 


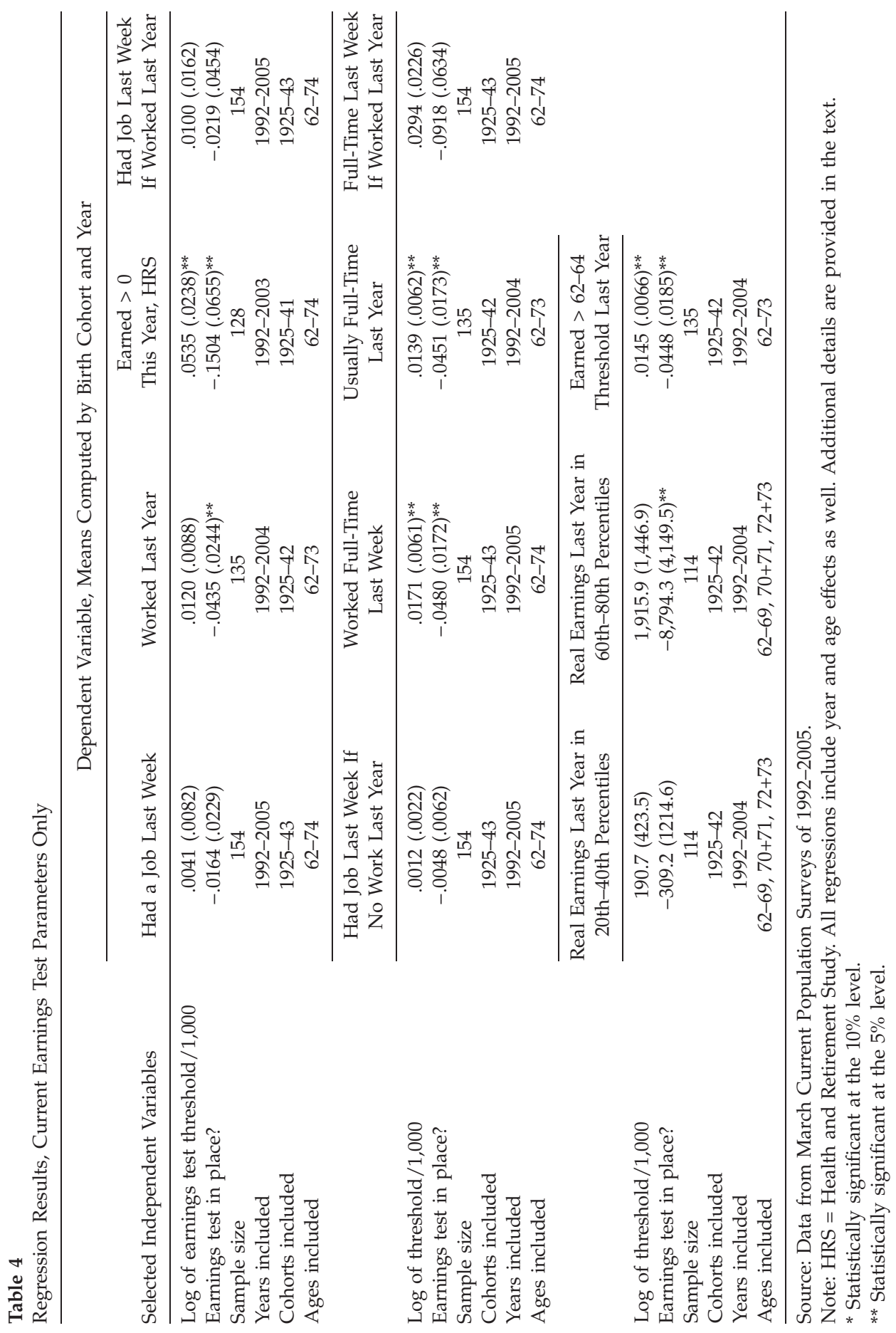


of the earnings threshold anticipated at age 62 significantly raises employment at all ages, and a greater number of years in which the earnings test is expected to apply, as anticipated at age 62, significantly reduces employment. A 10\% increase in the present value of the future threshold values results in almost a half percentage point increase in employment at the current age. The 1996 legislation raised the log of the present value of future threshold amounts by 0.40 , when comparing the cohort reaching age 62 in 1995 versus 1996. This implies a $0.40 \times$ $0.0445=1.8$ percentage point increase in employment for the latter cohort, which is a sizable share of the 5-6 point gain for workers in their 60 s throughout the period we examine.

Next it should be noted that the results are sensitive to the definition of work status, as we also found for the preliminary results in table 4. When the dependent variable is defined as working at all during the year rather than having a job last week, the estimated effects of earnings test parameters that were anticipated at age 62 remain similar in magnitude but are no longer statistically significant. The current value of the earnings test threshold is now larger and significant, with a $10 \%$ increase implying an 0.19 percentage point increase in employment (and recall that the 1996 legislation raised the threshold by close to $10 \%$ per year through 1999). When, instead, employment is defined based on having any annual earnings in the HRS, several of the coefficients are substantially larger; the estimated effects of the earnings threshold and earnings test dummy values that were anticipated at age 62 are more than twice as large.

A last point with regard to the employment results arises from an interesting contrast with the graphs presented earlier. In figure 3, we demonstrated the importance of controlling for last year's labor supply when evaluating the effect of current earnings test parameters. In table 5, controlling for earnings test parameters that were anticipated well in the past helps deal with these concerns. Earnings test parameters anticipated at age 62 have sizable effects on overall employment but not on current employment conditional on working last year. On the other hand, earnings test parameters that are currently anticipated until age 69 have bigger, though still insignificant, effects on the latter than on the former.

When we turn our focus to full-time employment in the middle panel of table 5, the results are generally similar, which is unsurprising because liberalizing the earnings test should encourage more full-time work at the expense of either part-time work or employment. The values of earnings test parameters that were anticipated at age 62 have significant effects on working full-time last week, and they are very similar in 


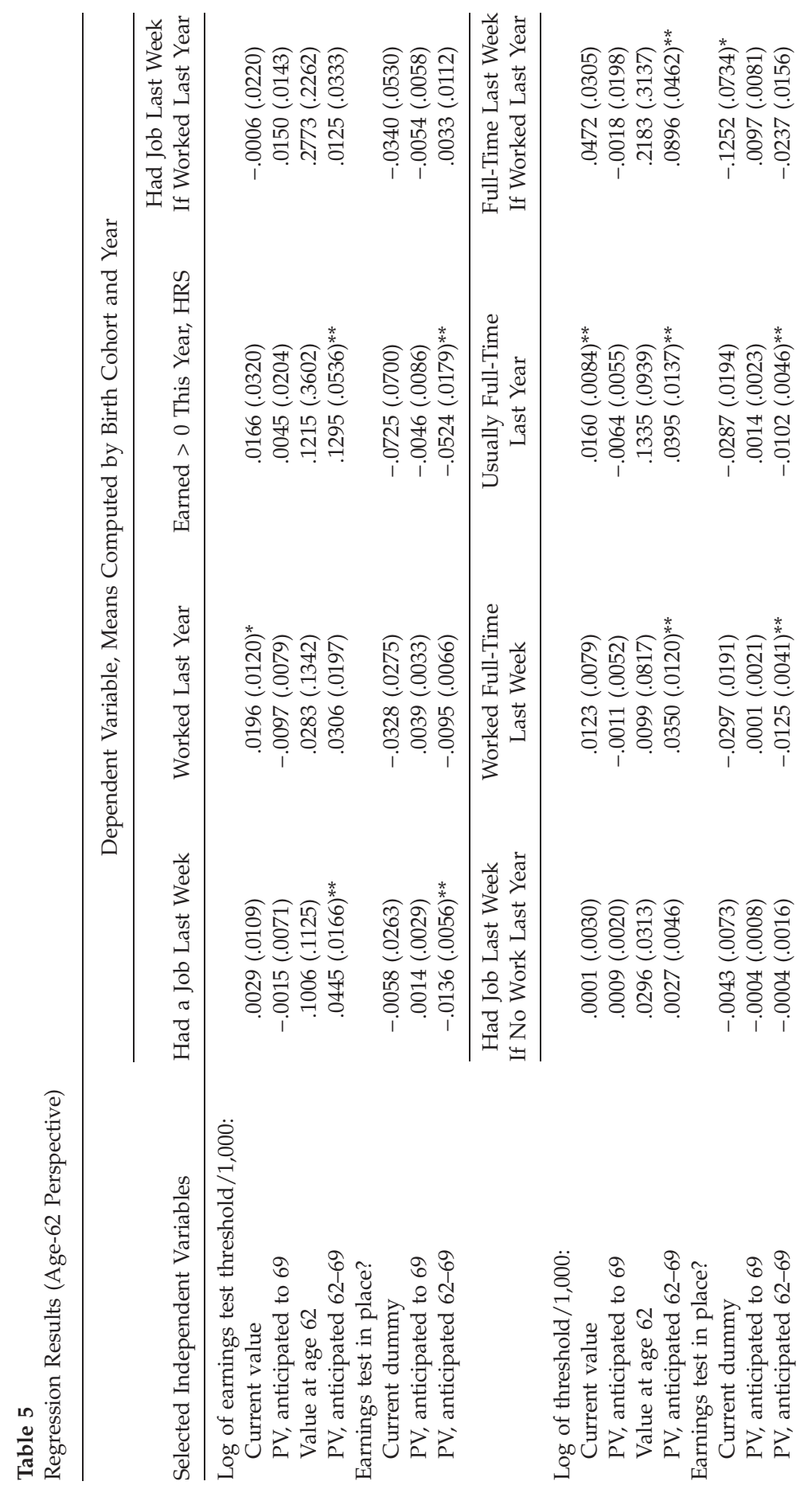




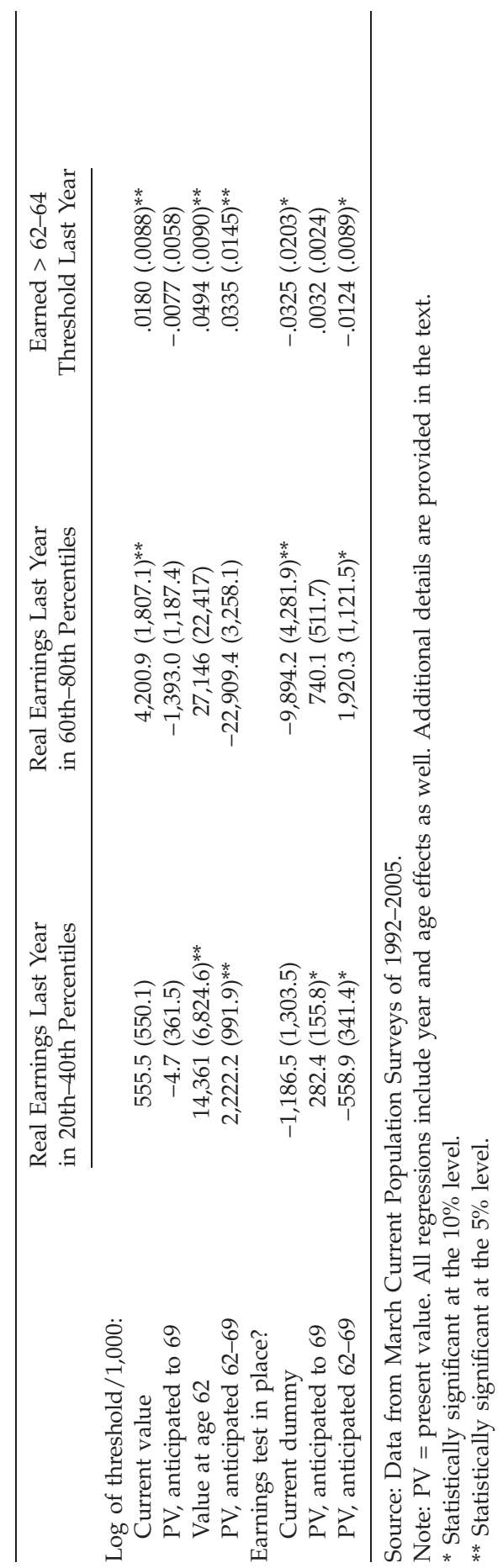




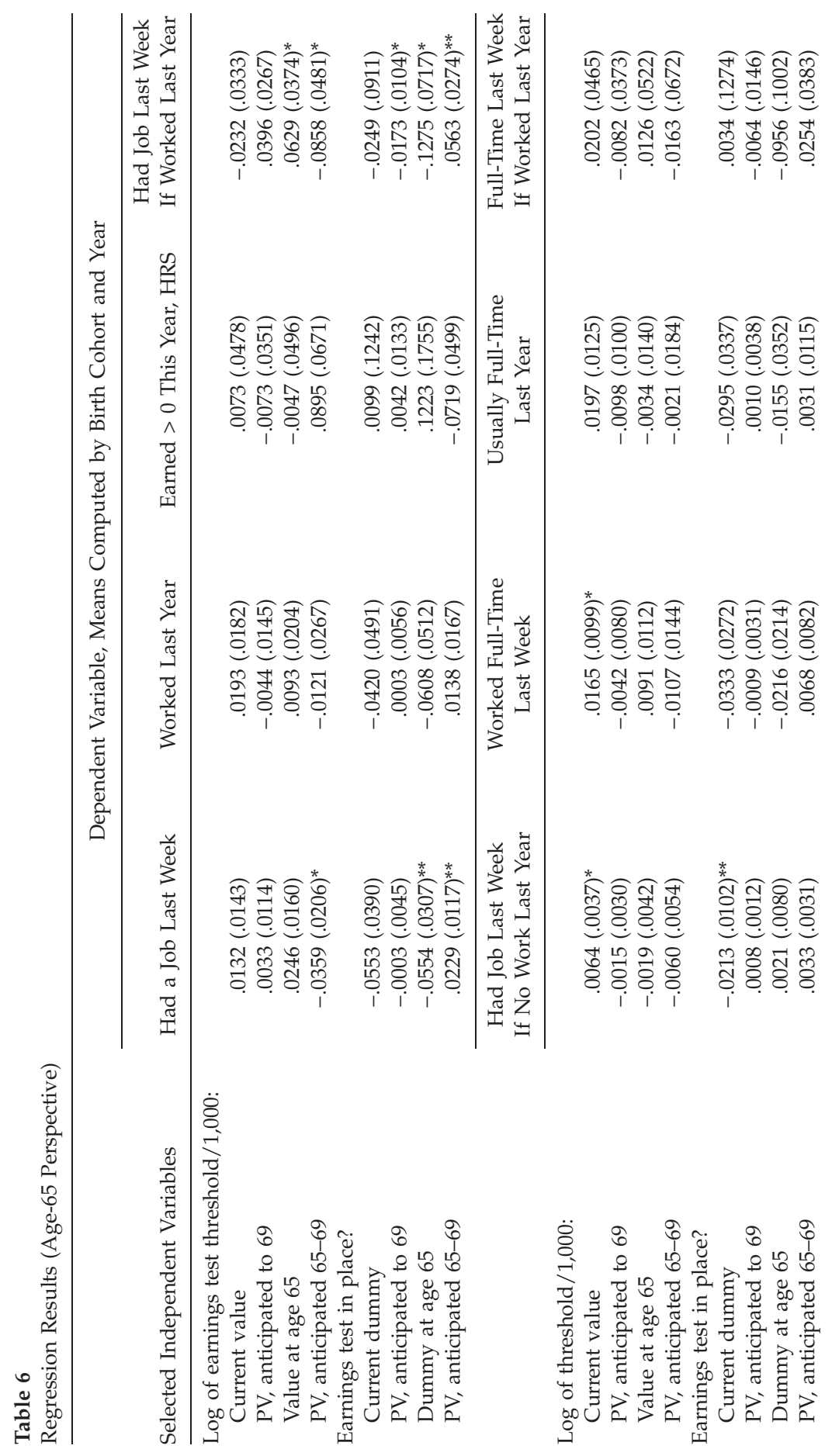




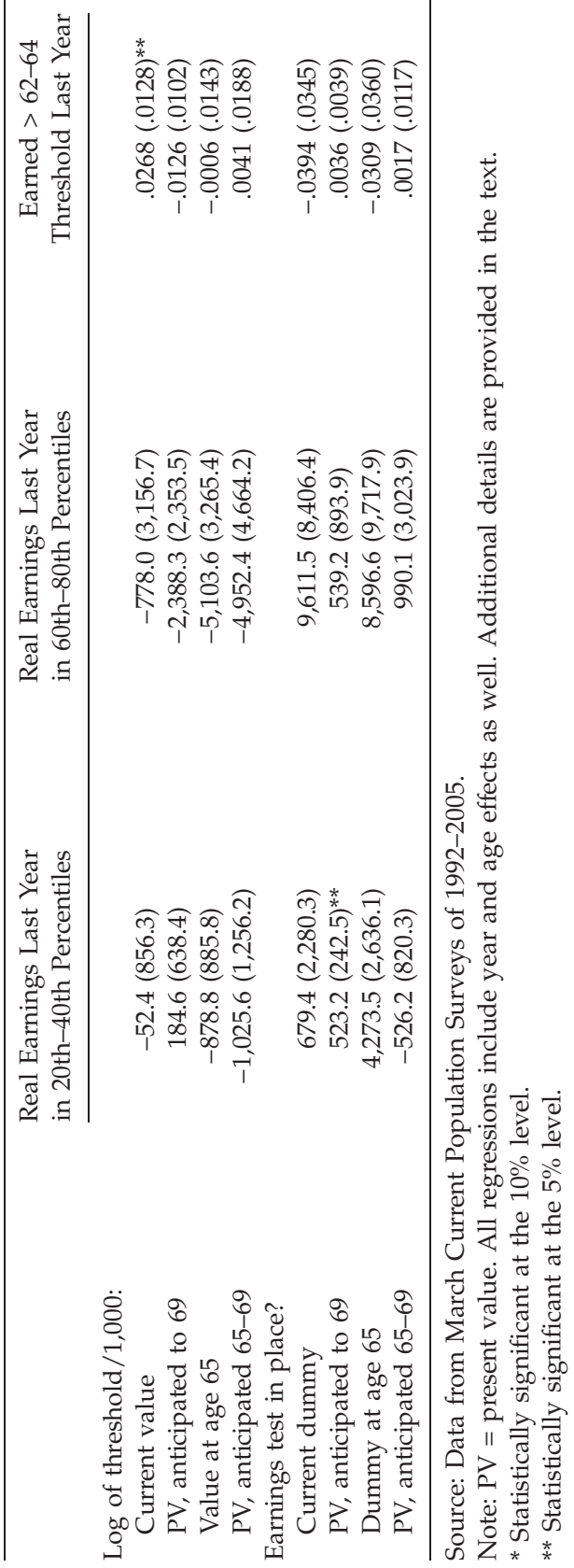


magnitude to the first set of results we discussed for having a job last week. The current earnings test dummy now has a sizable negative and close to significant effect. We find greater effects for working fulltime last year than for working at all last year, with statistically significant effects for the current value of the threshold, almost significant effects for the current earnings test dummy, and statistically significant effects for both values as anticipated at age 62 .

In the lower panel of table 5, we analyze changes in earnings by looking at behavior on different parts of the earnings distribution and/or budget constraint. Song and Manchester (2007) found two interrelated effects. They showed that earnings in the 20th-40th percentiles declined somewhat for ages 65-69 after 2000, and earnings in the 60th-80th percentiles increased a great deal, showing that people responded by shifting their earnings up. However, it is less straightforward to undertake this analysis by doing a cross-age comparison, since the conditional earnings distribution differs greatly with age. We find several significant effects, but they are somewhat difficult to interpret, so we will discuss their implications in a simulation exercise momentarily.

Last, we also employed a simpler test by measuring the percentage of the full sample-workers and nonworkers-who had earnings above the earnings test threshold that applies at ages 62-64. This is a relatively low amount that rose by the rate of wage inflation throughout the period but was not affected by legislation, and it may capture persistent labor supply responses that begin at ages $62-64$. We find that several of the parameters have significant effects on the likelihood of earning more than the age 62-64 threshold. Higher values of the current and anticipated thresholds, along with the thresholds anticipated at age 62 , raise this likelihood, while the earnings test being in place or anticipated at age 62 to be in place for longer reduces it.

In table 6, we define the retrospective earnings test parameters from an age- 65 rather than an age-62 perspective, and we limit the sample to ages 65-74. We find fewer significant effects, possibly because we have lost information (since age- 65 surprises for a cohort are shorter lived than age-62 surprises) that helps to distinguish earnings test responses from underlying labor supply changes. Of interest, though, are significant effects that correspond to the patterns in figure $2 B$ and $2 C$. For example, the current earnings test threshold and current earnings test dummy significantly raise the proportion of the sample returning to work, which is driven by the immediate response in 2000 at ages 65-69 that we saw in figure 2C.

Understanding the overall effect of a change in earnings test rules, which alter actual and anticipated values over a period of time, is now 
more complicated. We use our estimates to simulate the elimination of the earnings test in 2000. To do so, we determine how current and anticipated values of the threshold and earnings test dummy were affected and then how those shifts got transmitted to labor supply via the estimated coefficients that we have discussed. Since the estimates for current measures of labor supply were often less robust, we focus on full-year measures. Recall, also, that the specifications are restrictive in allowing the earnings test to generate persistence by altering labor supply only at age 62 and not at other past ages.

When we predict the effect of eliminating the earnings test in 2000 on working at all during the year as reported in the CPS, we find increases at ages 66-68 of about a half percentage point and an increase at age 65 of 1.3 percentage points. The predicted effects on the same variable from the HRS are substantially greater. Employment in 2000 is predicted to rise by around 2 percentage points at ages $66-69$ and by 3.5 points at age 65 . As cohorts then age, employment remains about a percentage point (1.5) higher in 2001 and about a half a percentage point (0.9) higher in 2002 for ages 66-69 (age 65). Moreover, employment rates at younger ages increase by about 1 percentage point due to the shock to anticipated values.

We also find notable effects of the 2000 change on earnings at different parts of the distribution. We find declines of a few hundred dollars in average earnings in 2000 between the 20th and 40th percentiles of the earnings distribution and gains of up to a few thousand dollars in the 60th-80th percentiles. Consistent with this, we also find increases in the percentage earnings above the earnings threshold of a half to a whole percentage point for workers in their late 60s in 2000.

\section{Conclusions}

In this study, we consider several issues that have received little attention in studies of recent earnings test changes. First, while other studies have investigated the effects of the elimination of the earnings test in 2000 for ages 65-69, we also consider the increases in the earnings test threshold for the same age group that were instituted gradually beginning in 1996. The elimination in 2000 should be considered against a backdrop in which the earnings test threshold was already rising and was expected to reach considerable amounts in 2000-2002.

Second, we use data on labor force transitions to show that conditioning on last year's labor supply is important in identifying responses to earnings test changes in the current year. We find major differences in how workers and nonworkers responded to the recent changes, and 
we find that flows into full-time versus part-time work were altered as well.

Third, we develop a regression framework to analyze how the persistence of labor supply choices influenced responses to earnings test changes. Our results reveal significant effects of past and anticipated future earnings test rules on current labor supply. Overall, we predict that the elimination of the earnings test in 2000 raised employment among Health and Retirement Study respondents by around 2 percentage points at ages $66-69$ and 3.5 points at age 65 , with gains persisting as exposed cohorts aged and also arising at younger ages due to the shock to anticipated earnings test rules. These effects are masked when considering the impact of only current earnings test parameters. As a consequence, earnings test changes can affect labor supply of younger and older workers in addition to the directly affected group.

\section{Endnotes}

We would like to thank Jeff Brown for helpful comments and Wei Sun for outstanding research assistance. The research reported here was performed in part pursuant to a grant from the U.S. Social Security Administration (SSA) funded as part of the Retirement Research Consortium. The opinions and conclusions expressed are solely those of the authors and should not be construed as representing the opinions or policy of SSA, any agency of the federal government, or Boston College.

1. Economic theory predicts that the earnings test should deter labor supply only for people who expect to die sooner than average, who cannot borrow against their future increases in benefits, or who are poorly informed.

2. A series of earlier laws culminating in 1983 eliminated the earnings test at ages 70 and above.

3. It is reasonable to believe that the law changes were not anticipated in earlier years. The 1996 and 2000 laws were enacted early in the year (on March 29 and on April 7, respectively), and both were made retroactive to January 1. The 1996 law was not discussed in policy circles in the prior year. The Economic Report of the President of February 1999 discussed distortionary effects of the earnings test, but there was little media attention until bipartisan legislation was proposed in early 2000.

4. According to our tabulations using the March CPS of 1992-2005, \$30,000 slightly exceeds median nominal annual earnings - \$29,000 — of people aged 58-61 who worked the entire year and exceeds the 75th percentile value for people aged 66-69 who worked at all.

5. In making these comparisons, it is important to avoid confusing the absence of the earnings test (and hence of an earnings threshold) with the presence of the earnings test and a threshold of $\$ 0$. In table 4 , we impute a value for the threshold of $\$ 50,000$ to represent the absence of the earnings test after 1999. In our regression analysis, we instead attribute a value of 0 in those cases, while adding a dummy variable for the earnings test being in place. 2005 .

6. The DRC has been raised by a half percent every year since 1990 and reached $7 \%$ in

7. Simon (1996), Kristof (1997). Coile et al. (2002) found that many beneficiaries for whom the adjustment is actuarially fair or better claim benefits early at age 62, suggesting that the credits are not fully taken into account in the claiming decision either.

8. A very incomplete summary of this evidence includes Card (1990) on tied wagehours contracts; Altonji and Paxson (1988) on wage cuts associated with transitions to 
part-time work; and Hausman (1980) and Cogan (1981) on fixed costs of work. The relevance of such constraints in affecting retirement is summarized by Hurd (1996).

9. The earnings test may also affect younger workers through life cycle labor supply effects. Under this model, reducing the tax at older ages would lead to a shift in labor supply from younger to older ages; but given our focus on constraints on labor supply choices, we do not think that this type of intertemporal shifting is likely to dominate.

10. Of 65-69-year-olds working in the 1990s, $49.2 \%$ worked usual part-time hours (less than 35 per week), compared to $14.2 \%$ of 50-59-year-old men. These statistics are computed using supplemental weights for all men who worked last year in the March CPS from 1992 to 2000 (Friedberg 2002).

11. Testing the related prediction that people should avoid the nonconvex kink in the budget constraint is difficult because its location is difficult to measure for households with dependent benefits and for age-eligible workers who are not receiving benefits.

12. Gruber and Orszag (2003) and Song and Manchester (2007) also showed that Social Security benefit claiming rose when earnings test rules were relaxed. These results confirm that many people view the earnings test as a tax; otherwise claiming and labor supply decisions would be delinked if benefit deferrals (due to delayed claiming or due to the earnings test) were perceived as actuarially fair.

13. Gruber and Orszag (2003) and Haider and Loughran (2006) found no change in employment following the 1983 elimination of the earnings test for ages 70-71, in contrast to the results for 2000. Haider and Loughran employed the same data and methods to look at both changes; they speculated that the older age of those affected in 1983 limited their response, and they showed a diminishing response by age in 2000.

14. Our data extends the analysis of others by another 2-3 years. Song and Manchester (2007) and Haider and Loughran (2006) had the advantage of accurate information on earnings, benefits, and birthdays from administrative panel data. Our data from the HRS also include administrative records on earnings. They could not observe hours of work in their data and so distinguish the contribution of hours choices to earnings. While Haider and Loughran also used survey data that were matched to administrative records, those data sets from the late 1970s and early 1980s are quite old.

15. Tran 2005 matched across monthly CPSs to generate a series of 1 -year panels, but doing so induces attrition bias that our use of the CPS avoids. Households at a particular address are in the CPS for 4 consecutive months, out for 8 months, then in for 4 more months. The CPS interviews the new household at that address if the old households moves. Since moving out of jobs is correlated with moving out of one's house, matching will undercount labor supply transitions and generate attrition bias.

16. We use the CPS basic weights and apply the adjustment factors developed by Povlika and Miller (1998) for pre-1994 weights. Stewart $(2002,2005)$ recommends this procedure when combining retrospective and current data in the March surveys across this time period, as we do, because the 1994 redesign of the CPS had a small effect on the coding of employment and unemployment.

17. Gustman and Steinmeier (1999) examine selection issues associated with refusals. In the Original HRS sample of 1992, 71.6\% were matched to their Social Security earnings data. While some observable variables like race, wealth, and education have statistically significant effects on matching, they explain little of the overall variation.

18. It is clear from the HRS that people are more likely to return to work after absences that are shorter than 1 year.

19. When we look at age groups in the March CPS, we avoid at this point including people aged 65, since we do not know when they turned 65 .

20. As a deflator, we use Social Security earnings growth, as reflected in the normal annual increases in the earnings test threshold.

21. Song and Manchester (2007) report annual earnings at the 60th, 70th, and 80th percentiles in 1999 for white males aged $65-69$ of $\$ 14,961, \$ 21,901$, and $\$ 34,874$. In our data, the amounts are $\$ 18,000, \$ 26,374$, and $\$ 45,000$.

22. When we test the joint significance of the earnings test parameters, there are a few specifications for which the $p$-value on the $F$-statistic for all the parameters taken together is lower than the $p$-values on the current values tested separately from the past and anticipated future values. 


\section{References}

Altonji, Joseph, and Christina Paxson. 1988. "Labor Supply Preferences, Hours Constraints, and Hours-Wage Trade-offs." Journal of Labor Economics 6, no. 2 (April): 254-76.

Berkovec, James, and Steven Stern. 1991. "Job Exit Behavior of Older Men." Econometrica 69, no. 1:189-210.

Burtless, Gary, and Robert A. Moffitt. 1985. "The Joint Choice of Retirement Age and Postretirement Hours of Work." Journal of Labor Economics 3, no. 2 (April): 209-36.

$\rightarrow$ Card, David. 1990. "Labor Supply with a Minimum Hours Threshold." CarnegieRochester Conference Series on Public Policy 33 (Autumn): 137-68.

$\rightarrow$ Cogan, John F. 1981. "Fixed Costs and Labor Supply." Econometrica 49, no. 4 (July): 945-63.

$\rightarrow$ Coile, Courtney, Peter Diamond, Jonathan Gruber, and Alain Jousten. 2002. "Delays in Claiming Social Security Benefits." Journal of Public Economics 84 , no. 3 (June): 357-86.

Economic Report of the President. 1999. Washington, DC: U.S. Government Printing Office (February).

Friedberg, Leora. 1998. "The Social Security Earnings Test and Labor Supply of Older Men." Tax Policy and the Economy 12:121-50.

$\rightarrow-$ 2000. "The Labor Supply Effects of the Social Security Earnings Test." Review of Economics and Statistics 82, no. 1 (February): 48-63.

—_. 2002. "The Trend towards Part-Time Work among Older Workers." Manuscript, University of Virginia.

- 2007. "The Recent Trend towards Later Retirement." An Issue in Brief, series 9 (March), Center for Retirement Research, Boston College.

Gruber, Jonathan, and Peter Orszag. 2003. "Does the Social Security Earnings Test Affect Labor Supply and Benefits Receipt?" National Tax Journal 56 (December): 755-73.

$\rightarrow$ Gustman, Alan, and Thomas Steinmeier. 1986. "A Structural Retirement Model." Econometrica 54, no. 3 (May): 555-84.

- 1999. "What People Don't Know about Their Pensions and Social Security: An Analysis Using Linked Data from the Health and Retirement Study." Working Paper no. 7368, NBER, Cambridge, MA.

—. 2004. "The Social Security Retirement Earnings Test, Retirement and Benefit Claiming." Working Paper no. 10905, NBER, Cambridge, MA.

Haider, Steven, and David Loughran. 2006. "Do Elderly Men Respond to Taxes on Earnings? Evidence from the Social Security Retirement Earnings Test." Manuscript, Michigan State University.

$\rightarrow$ Hausman, Jerry A. 1980. “The Effect of Wages, Taxes, and Fixed Costs on Women's Labor Force Participation." Journal of Public Economics 14:161-94.

Hurd, Michael. 1996. "The Effect of Labor Market Rigidities on the Labor Force Behavior of Older Workers." In Advances in the Economics of Aging, ed. David Wise, 11-58. Chicago: University of Chicago Press.

Kristof, Kathy. 1997. "Personal Finance." Los Angeles Times, September 5, D5.

Povlika, Anne, and Steven Miller. 1998. "The CPS after the Redesign: Refocusing the Economic Lens." In Labor Statistics Measurement Issues, ed. J. Haltiwanger, M. Manser, and R. Topel, 249-86. Chicago: University of Chicago Press.

$\rightarrow$ Reimers, Cordelia, and Marjorie Honig. 1993. "The Perceived Budget Constraint under Social Security: Evidence from Reentry Behavior." Journal of Labor Economics 11, no. 1 (January): 184-204. 
1996. "Responses to Social Security by Men and Women: Myopic and Far-Sighted Behavior." Journal of Human Resources 31, no. 2 (Spring): 359-82.

$\rightarrow$ Ruhm, Christopher. 1990. "Bridge Jobs and Partial Retirement." Journal of Labor Economics 8, no. 4 (October): 482-501.

$\rightarrow$ Rust, John, and Christopher Phelan. 1997. "How Social Security and Medicare Affect Retirement Behavior in a World of Incomplete Markets." Econometrica 65, no. 4 (July): 781-831.

Saez, Emmanuel. 2005. “Do Taxpayers Bunch at Kinkpoints?” Manuscript, University of California, Berkeley.

Simon, Ruth. 1996. "How to Be Sure You Never Go Broke." Money 25 (October): $100-114$.

Song, Jae, and Joyce Manchester. 2007. "New Evidence on Earnings and Benefit Claims Following Changes in the Retirement Earnings Test in 2000." Journal of Public Economics 91, nos. 3-4 (April): 669-700.

Stewart, Jay. 2002. "Recent Trends in Job Stability and Job Security: Evidence from the March CPS." BLS Working Paper 356 (March), U.S. Bureau of Labor Statistics, Washington, DC.

— 2005. "Using March CPS Data to Analyze Labor Market Transitions." Manuscript (July), U.S. Bureau of Labor Statistics, Washington, DC.

Tran, Bac. 2005. "The Effect of the Repeal of the Retirement Earnings Test on the Labor Supply of Older Workers." Manuscript, University of Maryland.

U.S. Social Security Administration. 2005. Annual Statistical Supplement to the Social Security Bulletin, 2005. Washington, DC: Social Security Administration.

Vroman, Wayne. 1985. "Some Economic Effects of the Retirement Test." In Research in Labor Economics, vol. 7, ed. Ronald Ehrenberg. Greenwich, CT: JAI. 
